\title{
Non-tumor cells from an MSH2-null individual show altered cell cycle effects post-UVB
}

\author{
KELLY A.D. NARINE ${ }^{1 *}$, KATHLEEN E.A. FELTON ${ }^{1,2^{*}}$, ARABESQUE A.M. PARKER ${ }^{1}$, \\ VICTOR A. TRON ${ }^{2}$ and SUSAN E. ANDREW ${ }^{1}$ \\ Departments of ${ }^{1}$ Medical Genetics, ${ }^{2}$ Laboratory Medicine and Pathology, \\ University of Alberta, Edmonton, Alberta, Canada
}

Received May 8, 2007; Accepted July 30, 2007

\begin{abstract}
The multi-functionality of the DNA mismatch repair (MMR) proteins has been demonstrated by their role in regulation of the cell cycle and apoptosis, as well as DNA repair. Using a unique $M S H 2^{-/-}$non-tumor human lymphoblastoid cell line we show that MMR facilitates G2/M arrest after UVB-induced DNA damage. Deficiency in MSH2 leads to a decrease in the induction of G2/M cell cycle checkpoint following UVB radiation in MSH2-null non-tumor cells. We also show evidence that the above-mentioned cells deficient in MSH2 have decreased levels of key cell cycle proteins such as CHK1 phosphorylated at Ser345, CDC25C phosphorylated at Ser216 and CDC2 phosphorylated at Tyr15, Thr14, compared to MSH2-proficient cells after UVB radiation. In addition, we demonstrate an altered p53 protein in the MSH2-null cell line. Our data show that the MMR protein $\mathrm{MSH} 2$ is involved in the regulation of normal cell cycle response after UVB-induced DNA damage.
\end{abstract}

\section{Introduction}

The DNA mismatch repair (MMR) system ensures replication fidelity by repairing small insertion-deletion loops and single base mismatches involving normal or damaged bases that have not been repaired by DNA polymerase proofreading. Hereditary non-polyposis colorectal cancer (HNPCC) is associated with germline mutations in one of the MMR genes and subsequent loss of MMR function in tumors, while a significant number of sporadic cancers also demonstrate loss of MMR function and genomic instability (1). These indices

Correspondence to: Dr Susan E. Andrew, Department of Medical Genetics, 8-33 Medical Sciences Bldg., University of Alberta, Edmonton, Alberta T6G 2H7, Canada

E-mail: susan.andrew@ualberta.ca

${ }^{*}$ Contributed equally

Key words: DNA mismatch repair, MSH2, UVB, cell cycle arrest, DNA damage, p53 exhibit the importance of the MMR proteins in maintaining genomic stability and in the avoidance of tumorigenesis (reviewed in refs. 2,3).

In mammals MMR is initiated by the binding of the MSH2-MSH6 heterodimer (MutS $\alpha$ ) to base-base mismatches and small loops or the MSH2-MSH3 heterodimer (MutSß) that binds primarily to larger insertion/deletion loops. A second heterodimer consisting of MLH1 bound to PMS2 or MLH3 is subsequently recruited to the mismatched site. The affected DNA strand is cleaved and removal of the mismatch is followed by resynthesis and religation of the DNA strand (reviewed in ref. 4). In addition to repairing post-replicative errors, MMR can also recognize and remove mispairs involving DNA adducts or chemical modifications produced by exogenous agents, such as $\mathrm{O}^{6}$-methylguanine (5-8).

UVB radiation (290-320 $\mathrm{nm}$ ) is readily absorbed by DNA, inducing the formation of the DNA lesions cyclobutane pyrimidine dimers (CPDs) and 6-4 photoproducts (6-4 PPs). These photo-lesions are primarily removed by nucleotide excision repair (NER). The role of MMR in post-UV responses remains controversial in part due to the diversity of model organisms, UV dosage employed and recently retracted data (reviewed in ref. 9). In mammalian cells, the MutS heterodimer binds to UVB-induced mismatch/photoproduct compound lesions $(10,11)$. Evidence exists both for and against a role for MMR in the transcription coupled repair of CPDs (reviewed in ref. 9). MMR does not participate in the excision and/or repair of photoproducts, but may still be required to counteract the acquisition of mismatches due to error-prone translesion synthesis through these photoproducts, and therefore is important for the suppression of UV-induced mutagenesis and subsequent tumorigenesis.

Recent studies have shown that the MMR proteins are multi-functional, with roles in the regulation of cell cycle, apoptosis, homeologous recombination, as well as DNA repair (reviewed in ref. 12). Increasing evidence suggests that MMR proteins have a role in recognizing DNA damage and contributing to DNA damage responses independent of repair. Genetic mutants have allowed for the separation of function; MMR mutants defective in apoptosis are still functional in repair and vice versa (13-15). Using mouse models or cell lines deficient in MMR, recent findings have suggested a role outside of repair for MMR in the UV-induced DNA damage response (16-19). It has also been shown that MMR is a 
player in UVB-induced cell cycle arrest. van Oosten et al demonstrated that deficiency in Msh2 leads to a lower percentage of cells arrested in S-phase after UVB exposure as compared to wild-type cells, both in vivo and in vitro (20). Previous work in our laboratory has shown that primary mouse embryonic fibroblasts (MEFs) and in vivo keratinocytes deficient in Msh2 or Msh6 display lower levels of apoptosis following UVB exposure compared to wild-type cellular controls $(17,21)$. This is substantiated by in vivo studies by us and others that have shown that mice deficient for Msh2 or Msh6 develop skin tumors at lower cumulative doses of UVB compared to MMR-proficient littermates $(16,18,19)$, indicating a role for MMR in the cellular DNA damage response after UVB exposure and in prevention of skin cancer.

Recent observations indicate that recognition of UVinduced DNA adducts by sensor proteins, independent of NER, may be the first step in initiating UV-induced cell cycle arrest (22). Initiation of cell cycle checkpoint occurs rapidly after DNA damage and activation of ATM and ATR. Once active, ATM and ATR activate CHK1 and CHK2 which phosphorylate $\mathrm{CDC} 25 \mathrm{C}$, leading to its inhibition. $\mathrm{CDC} 2$ is then phosphorylated by MYT1 and WEE1 to induce G2/M arrest. The removal of these inhibitory phosphates on CDC2 is prevented by $\mathrm{CDC} 25 \mathrm{C}$ being inactive, thus inhibiting cell cycle progression into mitosis (reviewed in refs. 23,24).

Studies have shown diminished G2/M arrest in the absence of the MMR proteins MSH2, MLH1 or PMS2 in response to treatment by DNA damaging agents such as IR (25-27), cisplatin $(7,28)$ and 6 -TG $(6,29,30)$. One of the most characterized responses of MMR-deficient cells occurs following DNA damage induced by alkylating agents. Cells defective in MSH2 or MLH1 show no G2 arrest and are resistant to cytotoxicity induced by MNNG $(31,32)$. In addition, MMR proteins interact with proteins involved in the G2/M checkpoint pathway. Studies have shown that both Chk1 and Chk2/CHK2 interact with MSH2 $(33,34)$ and this interaction is enhanced after MNNG exposure (33). Using normal HeLa nuclear extracts, Wang and Qin demonstrated that MSH2 co-immunoprecipitates with ATR and ATRIP, both of which regulate the downstream phosphorylation of CHK1 (35).

Many studies that examine the roles of mammalian MMR use HNPCC tumor cell lines as an MMR-deficient model. These cancer cell lines have a mutator phenotype and may have acquired additional genetic alterations affecting their behavior (36-39). In contrast we have generated an EBVimmortalized lymphoblastoid cell line derived from normal blood obtained from an individual with bi-allelic MSH2 mutations resulting in an MSH2-null cell line (40). Despite identification of other MMR-null patients, this cell line is unique as an $\mathrm{MSH}^{-/}$, non-tumor human cell line. By comparing the cell cycle responses of non-tumor cells deficient for MSH2 to MMR-proficient cells, our studies show that MMR plays a role in facilitating G2/M arrest after UVB-induced DNA damage, prior to a neoplastic state. In addition, our studies show altered p53 protein migration in the MSH2-null individual. An altered p53 product has been observed in some but not all MMR-deficient tumor cell lines. Our data provide support that the MMR protein MSH2 is involved in the normal cell cycle response of cells post-UVB.

\section{Materials and methods}

Cell culture. Normal human lymphoblastoid cell lines MM $\left(\mathrm{MSH}^{+/+}\right)$, MR $\left(\mathrm{MSH}^{+/+}\right)$and JMG $\left(\mathrm{MSH}^{+/+}\right)$, MSH2-null human lymphoblastoid cell line $\mathrm{KM}\left(\mathrm{MSH}^{-/-}\right)$(40) and the human cell line LoVo (MSH2 $2^{---}$; ATCC) were cultured with RPMI-1640 plus 10\% fetal bovine serum (FBS; Gibco/ Invitrogen, Burlington, ON, Canada). The human lymphoblastoid cell lines MM $\left(\mathrm{MSH}^{+/+}\right)$, MR $\left(\mathrm{MSH}^{+/+}\right)$, JMG $\left(\mathrm{MSH}^{+/+}\right)$and $\mathrm{KM}\left(\mathrm{MSH}^{-/-}\right)$were immortalized by EBV. HEC1A cells from ATCC $\left(\mathrm{MSH6}^{-{ }^{--}}, \mathrm{PMS}^{-/}\right)$were cultured with McCoy's 5a medium plus $10 \%$ FBS. HEC59 cells

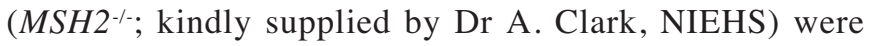
cultured with DMEM plus $10 \%$ FBS. All cell lines were grown in $5 \% \mathrm{CO}_{2}$ at $37^{\circ} \mathrm{C}$.

UVB irradiation. JMG $\left(\mathrm{MSH}^{+/+}\right)$and $\mathrm{KM}\left(\mathrm{MSH}^{-/-}\right)$cells were suspended in RPMI-1640 with no FBS and exposed to UVB light (290-320 nm) from a bank of six unfiltered UVB bulbs (FS20T12/UVB-BP, Light Sources Inc., Orange, CT), with the lid on to filter out UVC. The intensity of the UVB source was measured using IL1700 radiometer with a SED 240/UVB-1/W detector (International Light, Newburyport, MA). Following UVB irradiation, RPMI-1640 with FBS was added to reach a final concentration of $10 \%$ FBS.

Flow cytometry. JMG $\left(\mathrm{MSH}^{+/+}\right)$and $\mathrm{KM}\left(\mathrm{MSH}^{-/-}\right)$cells were pelleted and washed with RPMI-1640 without FBS and resuspended in 250-500 $\mu 1$ Vindelov propidium iodide stain (10 mM Tris pH 8.0, $10 \mathrm{mM} \mathrm{NaCl}, 700$ U RNase A, $0.075 \mathrm{mM}$ PI, $1 \mathrm{mM}$ NP40). Flow cytometry was performed using Becton Dickenson FACScan (Becton Dickenson, San Jose, CA), and the data were analyzed using ModFit LT, version 2.0 (Verity Software House, Topsham, ME).

Western blot analysis. JMG $\left(\mathrm{MSH}^{+/+}\right)$, KM $\left(\mathrm{MSH}^{-/-}\right)$, LoVo, HEC1A and HEC59 cells were harvested and lysed (50 mM Tris $\mathrm{pH} 7.5,10 \mathrm{mM} \mathrm{MgCl}_{2}, 1 \% \mathrm{SDS}$ ) and then sonicated in the presence of protease inhibitors (Complete protease inhibitor cocktail tablets; Roche Diagnostics, Laval, PQ, Canada). Lysates were diluted with protein loading buffer [2.5\% (wt/vol) SDS, 5\% (vol/vol) B-mercaptoethanol], separated by discontinuous SDS polyacrylamide gel electorphoresis and electro-transferred onto $0.45 \mu \mathrm{M}$ immobilon-P PVDF membrane (Fisher Scientific, Pittsburgh, PA) in Tris/glycine SDS transfer buffer. Immunoblots were blocked in 5\% (wt/vol) dry milk/TBST. Primary antibodies used were: CDC2, p53, p21 (\#610037, \#15791A, \#556431; BD Biosciences, Mississauga, ON, Canada), CDC2phos (Tyr15), CDC25Cphos (Ser216), CHK1phos (Ser345), p53phos (Ser15) (\#9111, \#9526, \#2341, \#9284; Cell Signaling Technology, Beverly MA), CDC25C, WEE1 (\#05-507, \#06-972; Upstate, Charlottesville, VA) and CHK1 (\#KAM-CC111; Stressgen Bioreagents, Victoria, BC, Canada). Antibody binding was visualized using the appropriate horseradish-peroxidase conjugated secondary antibody and ECL (Amersham Bioscience, Picataway, NJ) or ECL Plus (Amersham Bioscience) on Fuji SuperRX film (Fujifilm, Stamford, CT). To account for loading variations, the resulting densitometry values for the proteins of interest were normalized either to 
A

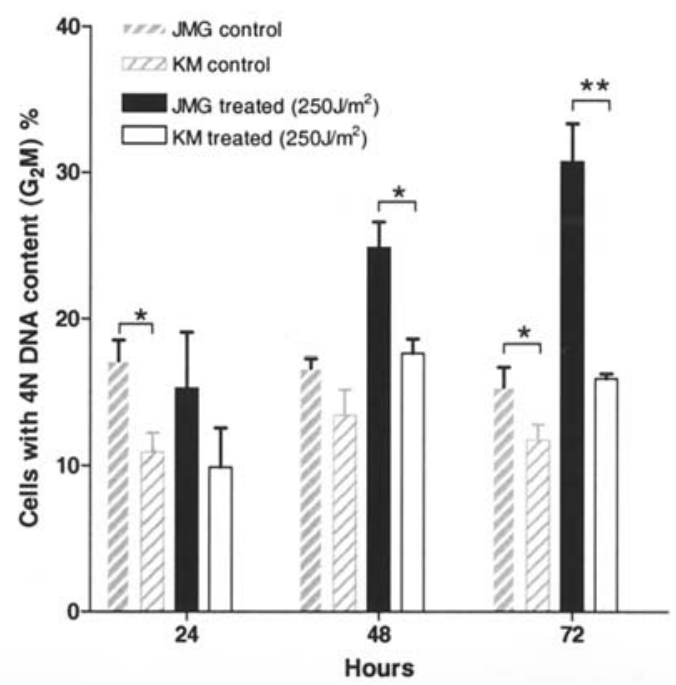

C

JMG (MSH2+/+)

Control

MG (MSH2+/+)

$250 \mathrm{~J} / \mathrm{m}^{2}$ UVB

KM (MSH2-/-)

Control
$24 \mathrm{~h}$
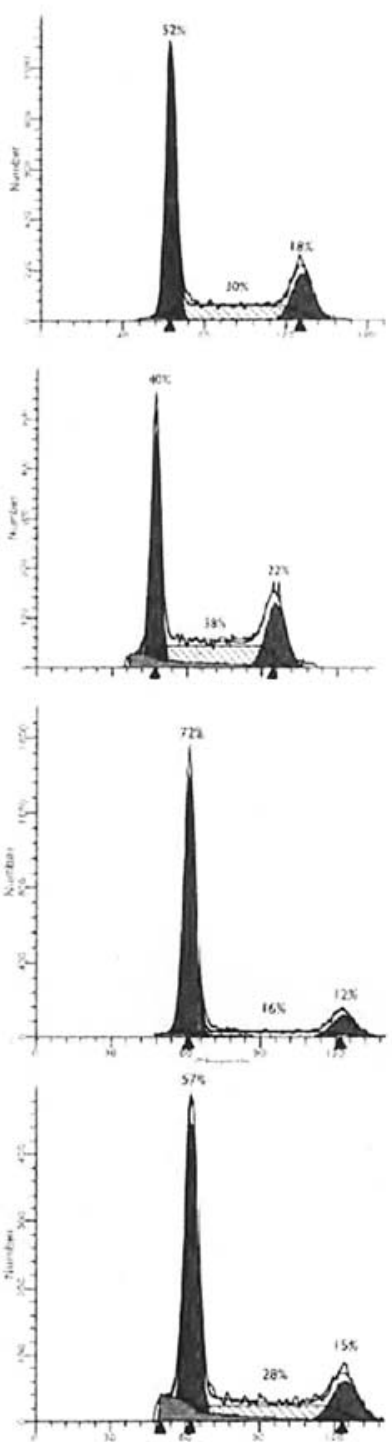

B

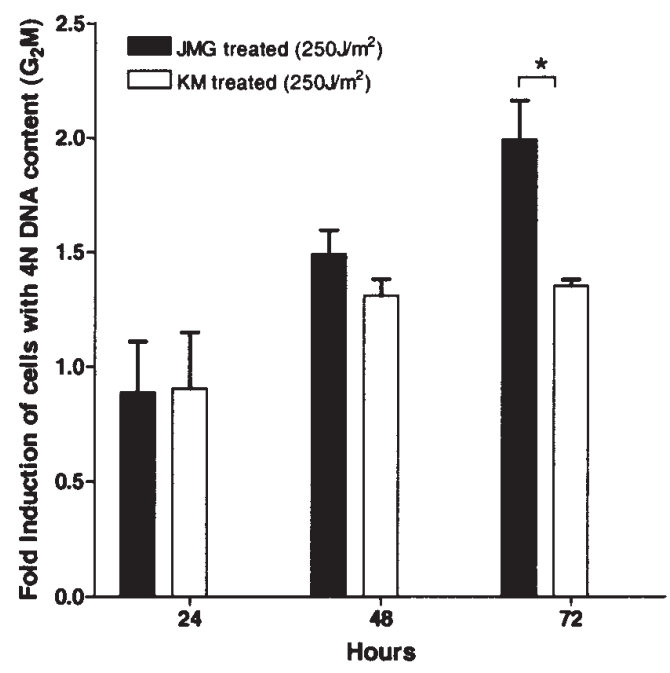

$48 \mathrm{~h}$

$72 \mathrm{~h}$
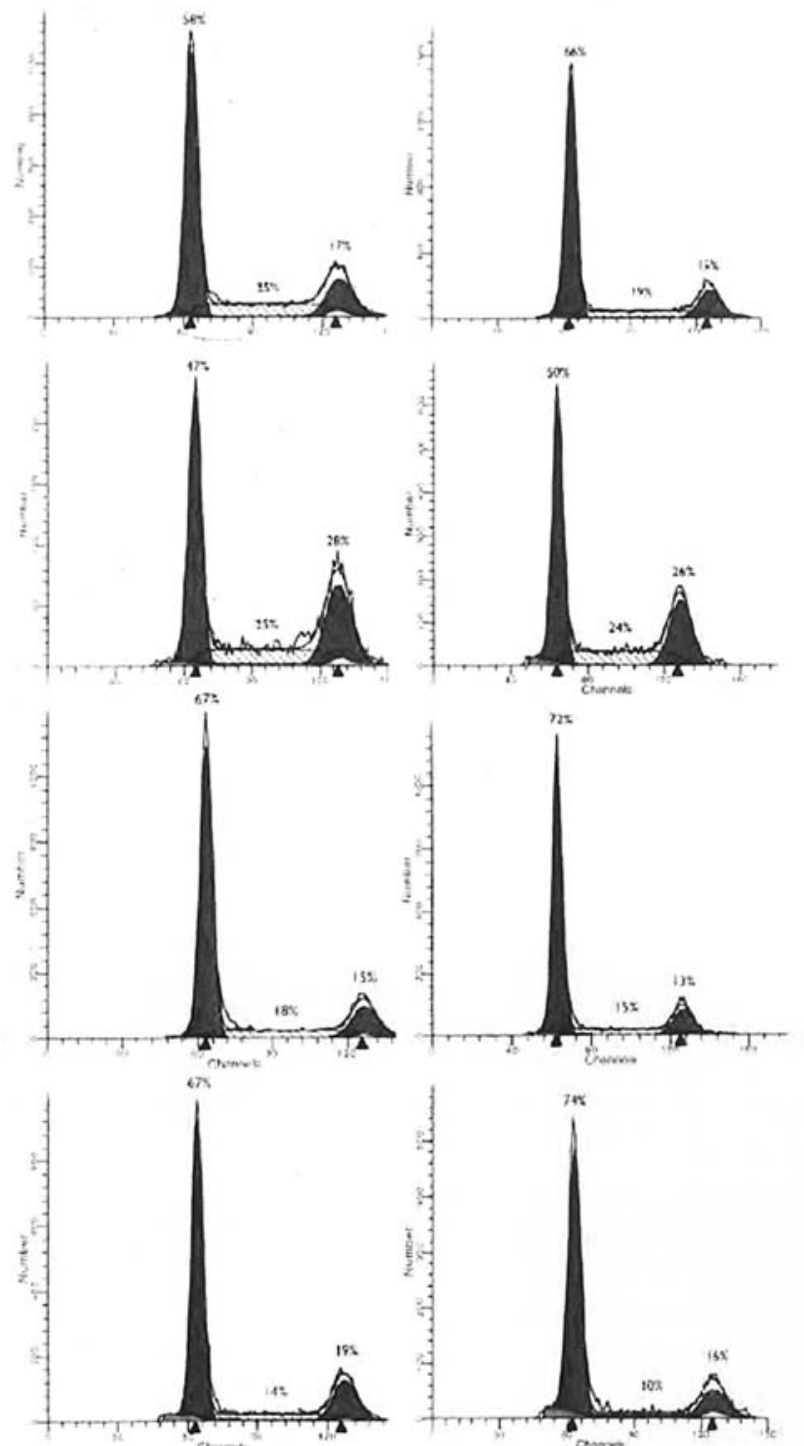

Figure 1. G2/M arrest in JMG $\left(\mathrm{MSH}^{+/+}\right)$and $\mathrm{KM}\left(\mathrm{MSH}^{-/}\right)$cells following UVB. (A) Untreated and $250 \mathrm{~J} / \mathrm{m}^{2} \mathrm{UVB}$-irradiated JMG $\left(\mathrm{MSH}^{+/+}\right)$and $\mathrm{KM}$ $\left(\mathrm{MSH}_{2}{ }^{-}\right)$cells were analyzed by flow cytometry to measure the percentage of cells with a $4 \mathrm{~N}$ DNA content (G2/M phase). Data represent mean of three experiments \pm SEM. Significance of the difference between the two cell types was determined using a Student t-test. Untreated controls at $24,72 \mathrm{~h}$ : $\mathrm{p}<0.05$, UVB-treated at $48 \mathrm{~h}: \mathrm{p}<0.05,72 \mathrm{~h}: \mathrm{p}<0.01$. (B) Fold induction of JMG $\left(M_{S H} 2^{+/+}\right)$and $\mathrm{KM}\left(\mathrm{MSH2}^{-/}\right)$cells with a $4 \mathrm{~N}$ DNA content $\left(\mathrm{G} 2 / \mathrm{M}\right.$ phase) after $250 \mathrm{~J} / \mathrm{m}^{2}$ UVB-irradiation. Data represent mean of three experiments \pm SEM. At $72 \mathrm{~h}: \mathrm{p}<0.05$. (C) Flow histograms of a representative trial showing the G1, S, and $\mathrm{G} 2 / \mathrm{M}$ phases of the cell cycle in untreated and $250 \mathrm{~J} / \mathrm{m}^{2} \mathrm{UVB}$-irradiated JMG $\left(\mathrm{MSH}^{+/+}\right)$and $\mathrm{KM}\left(\mathrm{MSH}^{-/-}\right)$cells. 


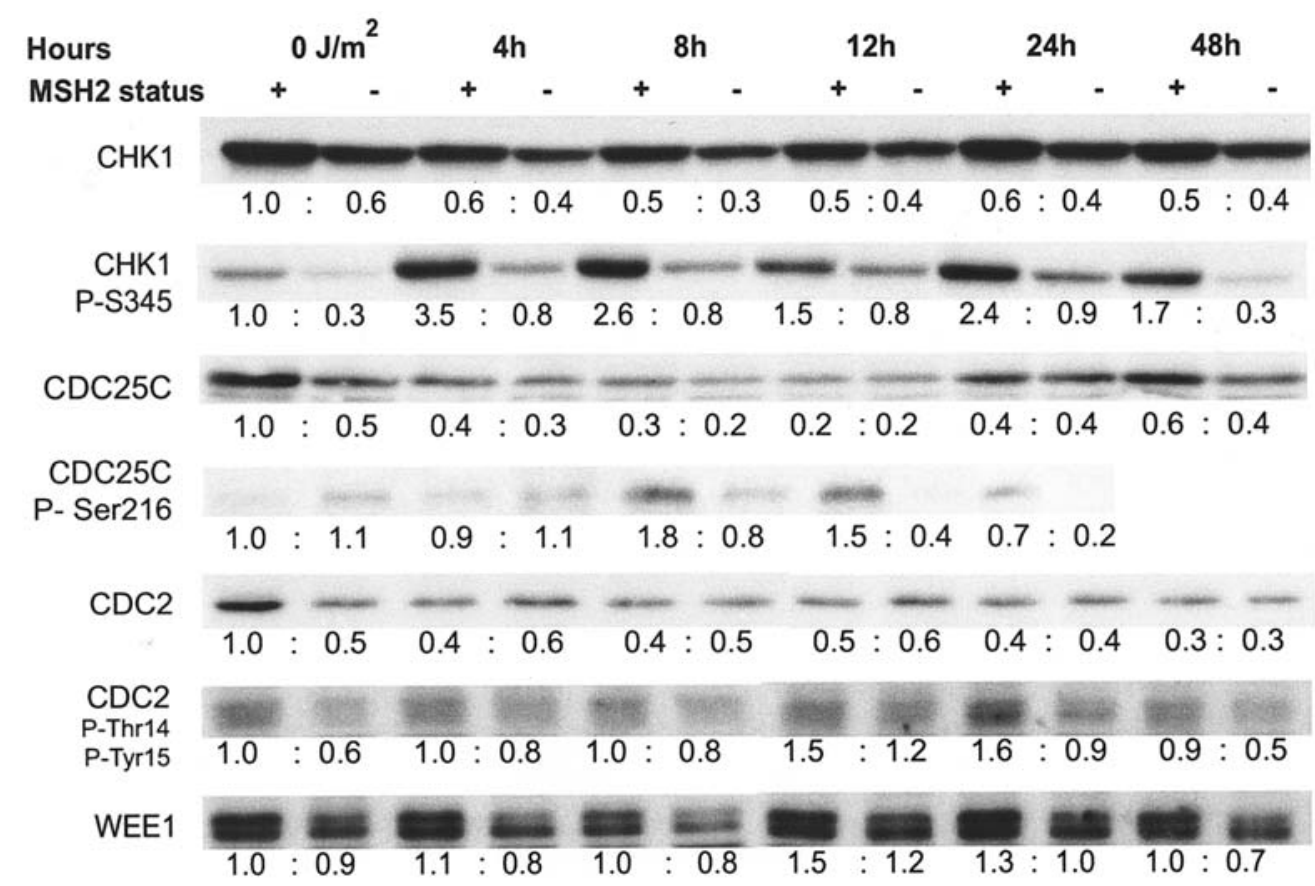

Figure 2. Cell cycle protein levels following UVB radiation. Protein levels of CHK1, CHK1-P (Ser 345), CDC25C, CDC25C-P (Ser 216), CDC2, CDC2-P (Tyr 15, Thr14), and WEE1 were analyzed by SDS-PAGE following $250 \mathrm{~J} / \mathrm{m}^{2} \mathrm{UVB}$ irradiation of JMG $\left(\mathrm{MSH}^{+/+}\right)$and $\mathrm{KM}\left(\mathrm{MSH}^{-/}\right)$cells.

gamma tubulin or to total protein levels as determined by amido black stain. Immunoblots were repeated 3 times and a representative figure is shown.

Phosphatase assay. JMG ( $\left.\mathrm{MSH}^{+/+}\right)$and $\mathrm{KM}\left(\mathrm{MSH}^{-/-}\right)$ protein lysates were incubated with $20 \mathrm{U}$ of calf intestinal alkaline phosphatase (Sigma, St. Louis, MO) at room temperature for $45 \mathrm{~min}$, followed by $45 \mathrm{~min}$ at $37^{\circ} \mathrm{C}$. The lysate was analyzed as described in the Western blot procedure. Mock-treated samples were treated under the same conditions without calf intestinal alkaline phosphatase.

Glycosylation assay. p53 was immunoprecipitated from JMG $\left(\mathrm{MSH}^{+/+}\right), \mathrm{MM}\left(\mathrm{MSH}^{+/+}\right), \mathrm{MR}\left(\mathrm{MSH}^{+/+}\right)$and $\mathrm{KM}\left(\mathrm{MSH}^{-/-}\right)$ protein lysates and run on an acrylamide gel with negative controls and positive control glycosylated proteins: RNase B and ovalbumin. Using the Glycoprofile ${ }^{\mathrm{TM}}$ III, the flourescent glycoprotein detection kit (Sigma) according to manufacturer's instructions, the amount of glycosylated protein was observed by fluorescence.

\section{Results}

Deficiency in MSH2 leads to decreased G2/M arrest post-UVB in non-tumor cells. The G1, S, and G2/M phases of the cell cycle were analyzed by flow cytometry following UVB irradiation of MSH2-proficient and -deficient lymphoblastoid cells. Untreated KM $\left(\mathrm{MSH}^{-/}\right)$cells had a decreased percentage of cells with $4 \mathrm{~N}$ DNA content (G2/M phase) compared to untreated JMG $\left(\mathrm{MSH}^{+/+}\right)$cells $(\mathrm{p}<0.05$; Fig. 1A). When data was normalized and fold induction of cells into 4N DNA content $(\mathrm{G} 2 / \mathrm{M})$ was analyzed, there was a lower fold induction in the percentage of cells in G2/M phase $72 \mathrm{~h}$ after UVB treatment in $\mathrm{KM}\left(\mathrm{MSH}^{-/}\right)$cells compared to JMG $\left(\mathrm{MSH}^{+/+}\right)$ cells [significant at $72 \mathrm{~h}$ post-UVB ( $<<0.05$; Fig. 1B)]. Therefore, deficiency in MSH2 leads to a reduction in the number of untreated cells in G2/M phase and also leads to a decrease in the induction of $\mathrm{G} 2 / \mathrm{M}$ cell cycle checkpoint following UVB radiation in MSH2-null non-tumor cells. Original flow histograms of a representative trial showing the $\mathrm{G} 1, \mathrm{~S}$, and $\mathrm{G} 2 / \mathrm{M}$ phases of the cell cycle of JMG $\left(\mathrm{MSH}^{+/+}\right)$ and $\mathrm{KM}\left(\mathrm{MSH}^{-/-}\right)$are shown (Fig. $\left.1 \mathrm{C}\right)$.

Deficiency in MSH2 leads to decreased induction of cell cycle proteins. Levels of proteins involved in the G2/M pathway were studied after UVB exposure and compared to untreated controls. Protein levels were normalized with respect to the amount of protein loaded and to the signal strength observed in the untreated MSH2 proficient cell line (Fig. 2). The levels of total CHK1 were lower in untreated $\mathrm{KM}\left(\mathrm{MSH}^{-/-}\right)$cell line compared to the untreated JMG $\left(\mathrm{MSH}^{+/+}\right)$control cell line. Following UVB radiation the levels of total CHK1 were modestly reduced in each of JMG $\left(\mathrm{MSH}^{+/+}\right)$and $\mathrm{KM}$ $\left(\mathrm{MSH}^{-/-}\right)$cell lines compared to their respective untreated controls. CHK1 is activated through phosphorylation by ATM and ATR at residue serine 345 (Ser345). KM ( $\mathrm{MSH}^{-/-}$) cells showed a decreased level of CHK1 phosphorylated at Ser345 in untreated cells compared to JMG $\left(\mathrm{MSH}^{+/+}\right)$ untreated cells. Following UVB radiation the levels of CHK1phos (Ser345) were not as high in $\mathrm{KM}\left(\mathrm{MSH}^{-/}\right)$cells as JMG $\left(\mathrm{MSH}^{+/+}\right)$cells from 4 to $48 \mathrm{~h}$. $\mathrm{KM}\left(\mathrm{MSH}^{-/}\right)$cells had sustained levels of CHK1phos (Ser345) from 4 to $24 \mathrm{~h}$ after UVB irradiation and returned to basal levels at $48 \mathrm{~h}$ (Fig. 2).

The integral driver of the transition between $\mathrm{G} 2$ phase and mitosis is the CDC2-cyclin B1 complex. Inhibitory phosphates on $\mathrm{CDC} 2$ are removed by $\mathrm{CDC} 25 \mathrm{C}$. Untreated $\mathrm{KM}\left(\mathrm{MSH}^{-/-}\right)$ cells had approximately half the amount of CDC25C as 

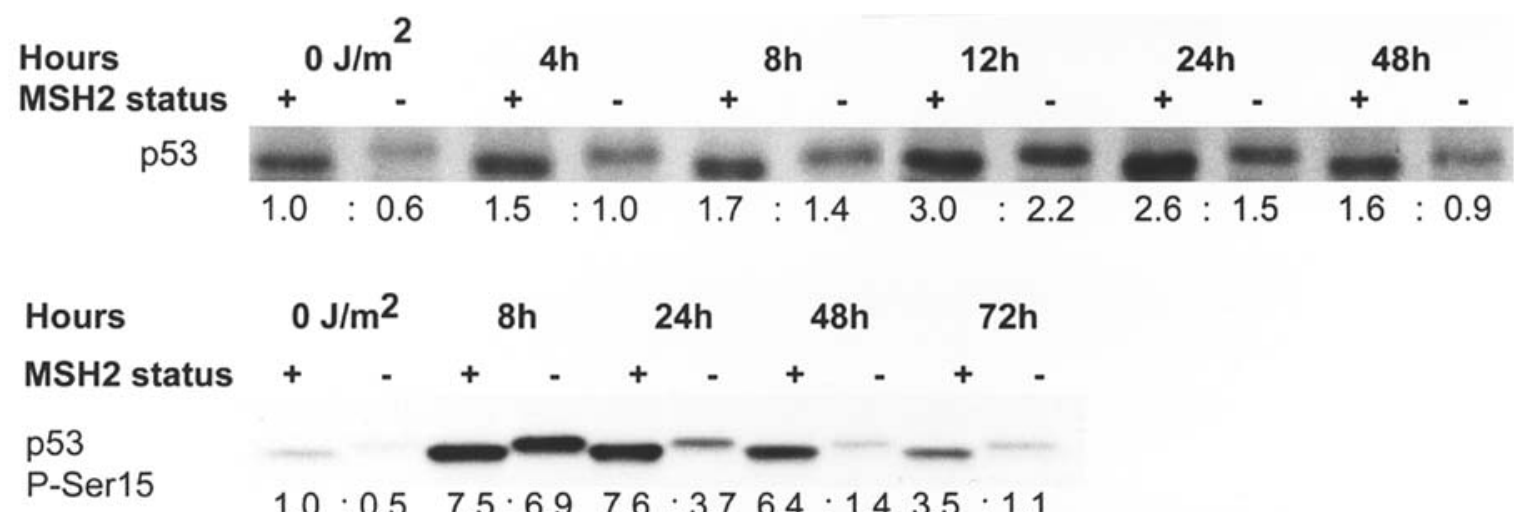

Figure 3. p53 and p53-phosphorylated levels following UVB radiation. Protein levels were analyzed by SDS-PAGE comparing p53 and phosphorylated p53 between $\mathrm{JMG}\left(\mathrm{MSH}^{+/+}\right)$and $\mathrm{KM}\left(\mathrm{MSH}^{-/-}\right)$cells following $250 \mathrm{~J} / \mathrm{m}^{2} \mathrm{UVB}$ radiation.

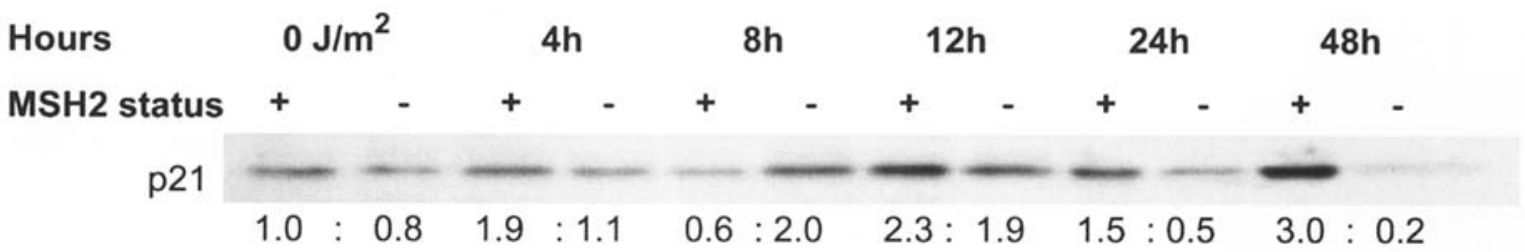

Figure 4. p21 levels following UVB radiation. Protein levels were analyzed by SDS-PAGE comparing p21 levels in JMG $\left(M S H 2^{+/+}\right)$and $\mathrm{KM}\left(\mathrm{MSH} 2^{-/ /}\right)$cells following $250 \mathrm{~J} / \mathrm{m}^{2} \mathrm{UVB}$ radiation.

untreated JMG $\left(\mathrm{MSH}^{+/+}\right)$cells. Following UVB radiation there was no substantial difference in the change of levels of $\mathrm{CDC} 25 \mathrm{C}$ between the JMG $\left(\mathrm{MSH}^{+/+}\right)$and $\mathrm{KM}\left(\mathrm{MSH}^{-/-}\right)$ cell lines. During G2/M arrest, CDC25C is inhibited by phosphorylation at serine 216 (Ser216). Although both JMG $\left(\mathrm{MSH}^{+/+}\right)$and $\mathrm{KM}\left(\mathrm{MSH}_{2}^{-/-}\right)$cells had approximately equal levels of CDC25Cphos (Ser216) when untreated and $4 \mathrm{~h}$ after UVB treatment, KM $\left(\mathrm{MSH}^{-/}\right)$cells had decreased levels of CDC25Cphos (Ser216) at 8, 12 and $24 \mathrm{~h}$ after UVB radiation compared to JMG $\left(\mathrm{MSH}^{+/+}\right)$cells (Fig. 2).

Total CDC2 protein levels were analyzed and untreated $\mathrm{KM}\left(\mathrm{MSH}^{-/-}\right)$cells had approximately half the amount as untreated JMG $\left(\mathrm{MSH}^{+/+}\right)$. CDC2 levels decreased following UVB radiation in the $\mathrm{JMG}\left(\mathrm{MSH}^{+/+}\right)$cell line and was maintained $>48 \mathrm{~h}$. Post-UVB exposure the level of CDC2 in the $\mathrm{KM}\left(\mathrm{MSH}^{-/}\right)$cell line remained unchanged from untreated levels. Protein analysis showed decreased amounts of CDC2phos (Tyr15, Thr14) levels in untreated KM (MSH2-/) cells compared to untreated JMG $\left(\mathrm{MSH}^{+/+}\right)$cells and at 12 and $24 \mathrm{~h}$ after UVB treatment in $\mathrm{KM}\left(\mathrm{MSH}^{-/}\right)$cells compared to JMG $\left(\mathrm{MSH}^{+/+}\right)$cells (Fig. 2). By $48 \mathrm{~h}$ the levels of CDC2phos (Tyr15, Thr14) returned to untreated levels in both cell lines.

One of the kinases that maintains inhibitory phosphates on CDC2 is WEE1. Following UVB radiation, $\mathrm{KM}\left(\mathrm{MSH}^{--/}\right)$ cells demonstrated consistently lower levels of WEE1 from 4 to $48 \mathrm{~h}$ compared to JMG $\left(\mathrm{MSH}^{+/+}\right)$, despite having approximately equal levels of WEE1 in untreated JMG $\left(\mathrm{MSH}^{+/+}\right)$and $\mathrm{KM}\left(\mathrm{MSH}^{-/-}\right)$cells (Fig. 2).

Deficiency in MSH2 leads to decreased induction of p53. The tumor suppressor p53 mediates DNA damage-induced cell cycle arrests at G1, G2/M and S phases (24). Total p53 levels were analyzed in $\mathrm{JMG}\left(\mathrm{MSH}^{+/+}\right)$and $\mathrm{KM}\left(\mathrm{MSH}^{-/-}\right)$cell lines in untreated cells and following UVB radiation (Fig. 3). Total p53 was decreased in the $\mathrm{KM}\left(\mathrm{MSH}^{-/-}\right)$cell line compared to JMG $\left(\mathrm{MSH}^{+/+}\right)$in untreated cells. In response to UVB radiation p53 levels increased in both cell lines, however, levels continued to be lower in $\mathrm{KM}\left(\mathrm{MSH}^{-/-}\right)$cells compared to JMG $\left(\mathrm{MSH}^{+/+}\right)$cells. There was $\sim 50 \%$ less activated p53 (phosphorylated at Serine 15) in untreated KM $\left(\mathrm{MSH}^{-/}\right)$cells compared to untreated JMG $\left(\mathrm{MSH}^{+/+}\right)$cells. After UVB radiation the levels of p53phos (Ser15) increased in both cell lines. At $24 \mathrm{~h}$ the level of p53phos (Ser15) was greatly decreased in $\mathrm{KM}\left(\mathrm{MSH}^{-/-}\right)$cells and no continued induction of p53phos (Ser15) was observed in the KM $\left(\mathrm{MSH}^{-/-}\right)$cell line.

Deficiency in MSH2 leads to decreased induction of p21.p21, a major downstream target of p53, was analyzed in JMG $\left(\mathrm{MSH}^{+/+}\right)$and $\mathrm{KM}\left(\mathrm{MSH}^{-/}\right)$cell lines following UVB radiation (Fig. 4). Protein levels of p21 were decreased in the $\mathrm{KM}\left(\mathrm{MSH}^{-/}\right)$cell line compared to JMG $\left(\mathrm{MSH}^{+/+}\right)$except at $8 \mathrm{~h}$ post-UVB. p21 protein level remained increased in JMG $\left(\mathrm{MSH}^{+/+}\right)$cells up to $48 \mathrm{~h}$ after UVB radiation. However, in $\mathrm{KM}\left(\mathrm{MSH}^{-/-}\right)$cells the level of p21 protein was not sustained and returned to normal levels $24 \mathrm{~h}$ after UVB radiation.

Altered p53 protein migration occurs in other MMR-deficient cell lines and is independent of phosphorylation and glycosylation in the KM cell line. Altered migration of p53 protein was observed by immunoblotting between the JMG $\left(\mathrm{MSH}^{+/+}\right)$ and $\mathrm{KM}\left(\mathrm{MSH}^{-/}\right)$cell lines. The p53 band of $\mathrm{KM}\left(\mathrm{MSH}^{-/-}\right)$ 


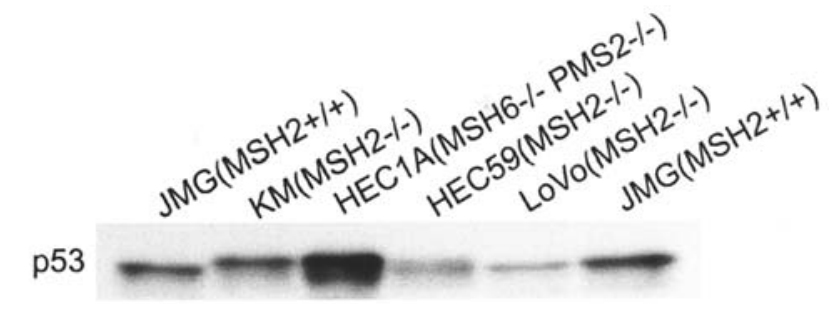

Figure 5. Altered migration of p53 observed in KM $\left(\mathrm{MSH}^{-/}\right)$, HEC1A $\left(\mathrm{MSH}^{-/} \mathrm{PMS}^{-/}\right)$and HEC59 cells $\left(\mathrm{MSH}^{-/}\right)$cell lines. Immunoblotting of p53 in JMG $\left(\mathrm{MSH}^{+/+}\right.$lymphoblastoid), KM ( $\mathrm{MSH}^{-/}$non-tumor lymphoblastoid), HEC1A ( $\mathrm{MSH}^{-\digamma} \mathrm{PMS}^{-/}$endometrial adenocarcinoma), HEC59 ( $\mathrm{MSH}_{2} \%$ endometrial adenocarcinoma) and LoVo $\left(\mathrm{MSH}_{2} \%\right.$ colon adenocarcinoma) cells with p53-DO1 antibody.

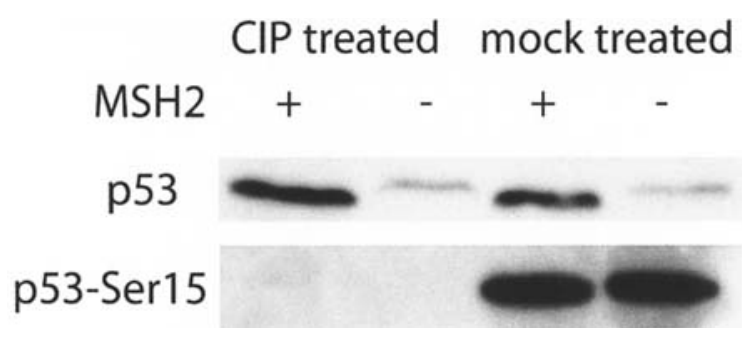

Figure 6. Altered migration of p53 is independent of phosphorylation. Immunoblotting showing cell lysates from JMG $\left(\mathrm{MSH}^{+/+}\right)$and $\mathrm{KM}\left(\mathrm{MSH}^{-/-}\right)$ treated and mock-treated with calf-intestinal phosphatase (CIP) to dephosphorylate proteins. The immunoblot was probed with p53-DO1 antibody to determine if phosphorylation accounts for the slower migration of the $\mathrm{p} 53$ protein observed in the $\mathrm{KM}\left(\mathrm{MSH}^{-/}\right)$cell line. p53-ser15 antibody was used as a control to confirm complete dephosphorylation.

migrated more slowly than that of JMG $\left(\mathrm{MSH}^{+/+} ;\right.$Fig. 3). To determine if this change was specific to the KM cells, or associated with general loss of MSH2 or other MMR proteins, an immunoblot comparing p53 in the JMG $\left(\mathrm{MSH}^{+/+}\right)$, KM $\left(\mathrm{MSH}^{-/}\right)$, HEC1A $\left(\mathrm{MSH6}^{-/} \mathrm{PMS}^{-/}\right.$endometrial adenocarcinoma), HEC59 (MSH2 $\%$ endometrial adenocarcinoma), and Lovo ( $M S H_{2} \%$ colon adenocarcinoma) cell lines was performed (Fig. 5). The results suggest that the HEC1A $\left(\mathrm{MSH6}^{-/} \mathrm{PMS2}^{-/}\right)$and HEC59 $\left(\mathrm{MSH}^{-/}\right)$cell lines show a slower migrating p53 band similar to that seen in KM $\left(\mathrm{MSH}^{-/}\right)$, as well as the normal $53 \mathrm{kDa}$ band, in comparison to JMG $\left(\mathrm{MSH}^{+/+}\right)$and $\mathrm{LoVo}\left(\mathrm{MSH}_{2}^{-/}\right)$. To investigate the migration difference in $\mathrm{p} 53$ further, the p53 cDNA was sequenced in JMG $\left(\mathrm{MSH}^{+/+}\right)$and $\mathrm{KM}\left(\mathrm{MSH}^{-/}\right)$cell lines. Sequence analysis demonstrated that both cell lines had wildtype sequence for $\mathrm{p} 53$ and were identical (data not shown). Thus, the difference in the migration pattern of p53 in KM $\left(\mathrm{MSH}^{--}\right)$was not due to a sequence alteration, including the common polymorphism c. $347 \mathrm{C}>\mathrm{G}$, Pro72Arg in p53 $(41,42)$. The $\mathrm{p} 53$ protein is extensively modified post-translationally. We found that the slower migration of p53 in the $\mathrm{KM}\left(\mathrm{MSH}^{2} /\right)$ cell line was independent of phosphorylation (Fig. 6) and glycosylation (data not shown). Further analysis of the p53 status in the $\mathrm{KM}\left(\mathrm{MSH}_{2}^{--/}\right)$cell line must be performed to explain the cause of the altered migration of p53 in the KM $\left(\mathrm{MSH}^{-\digamma}\right)$ cell line. G2/M cell cycle checkpoint showing potential position of MMR is shown in Fig. 7.

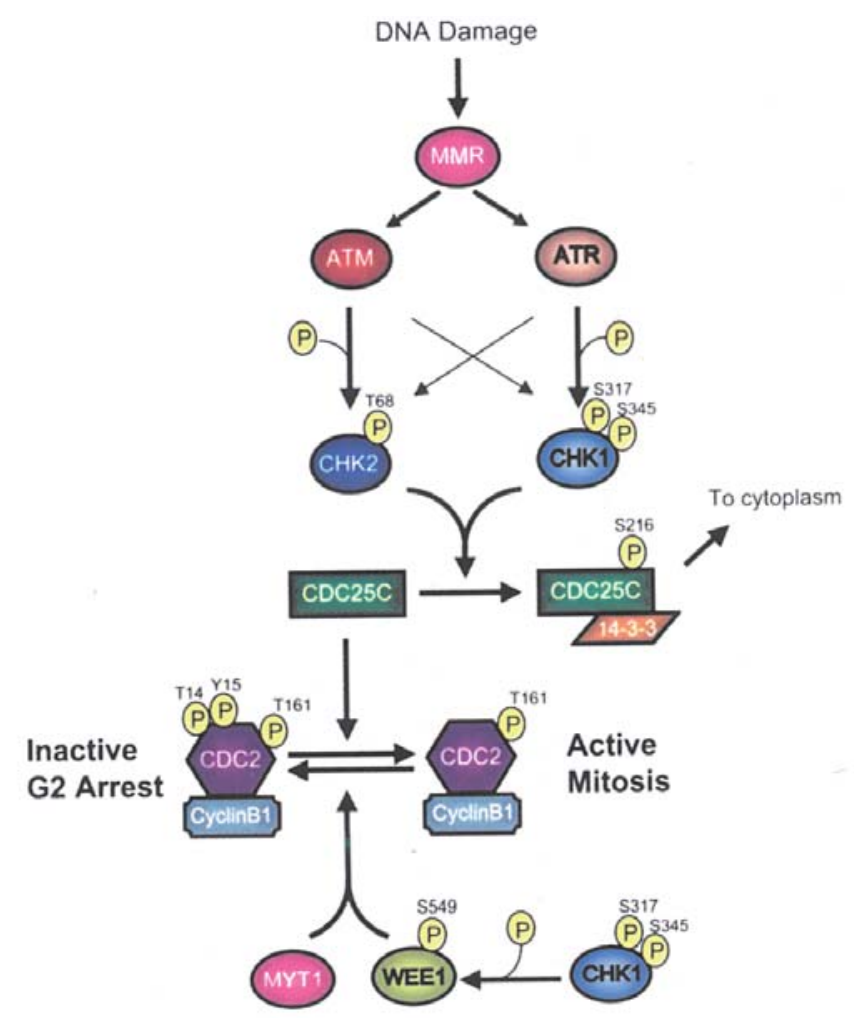

Figure 7. G2/M cell cycle checkpoint showing potential position of MMR. ATM and ATR are activated after DNA damage. Once active, ATM and ATR phosphorylate and activate CHK1 and CHK2. CHK1/2 phosphorylate and inhibit $\mathrm{CDC} 25 \mathrm{C}$, promoting interaction with 14-3-3 and movement of $\mathrm{CDC} 25 \mathrm{C}$ to the cytoplasm. Inhibiting CDC25C prevents the removal of inhibitory phosphates on $\mathrm{CDC} 2$ and prevents cell cycle progression into mitosis. CDC2 is phosphorylated at Thr14 and Tyr15 by MYT1 and WEE1 to induce G2/M arrest, but activated by phosphorylation at Thr161. Adapted from (64).

\section{Discussion}

Many studies have indicated the importance of a functional MMR system for the appropriate activation of cell cycle checkpoints in response to several types of DNA damage $(34,35,43-48)$. However, most of the cell cycle studies have been performed in MMR-deficient tumor cell lines. To ensure that the effects were due to loss of MMR and not to other mutations acquired during tumorigenesis, we assessed the influence of MSH2 in the cell cycle in a non-tumor cell line generated from an individual with bi-allelic MSH2 mutations resulting in an MMR-null phenotype (40). Complementation of the KM $\left(\mathrm{MSH}^{-/}\right)$cell line with wild-type $\mathrm{MSH} 2 \mathrm{cDNA}$ was unsuccessful. Thus, we compared the response of KM ( $\mathrm{MSH}^{--}$) cells to 3 wild-type cell lines: MM, MR and JMG $\left(\mathrm{MSH}^{+/+}\right)$; results from JMG are shown as a representative MMR-proficient cell line. UVB is the most physiologically important type of UV radiation as it penetrates the ozone layer and induces DNA lesions such as CPDs and 6-4PPs (reviewed in ref. 49). We have previously shown that MMR is important in the prevention of UVB-induced skin cancer via its role in triggering UVB-induced apoptosis (16). By demonstrating that the lack of MSH2 leads to abrogated G2/M cell cycle arrest as well as altered levels and decreased induction of several integral cell cycle proteins, including p53 post- 
UVB, we have shown that the MMR system is an important component in the cell cycle response of normal, non-tumor cells to UVB-induced DNA damage.

Our data illustrate that an MSH2-deficient non-tumorigenic human cell line shows a significant reduction in the percentage of untreated cells in $\mathrm{G} 2 / \mathrm{M}$ phase $(\mathrm{p}<0.05)$ and a partial reduction in $\mathrm{G} 2 / \mathrm{M}$ arrest $48(\mathrm{p}<0.05)$ and $72 \mathrm{~h}(\mathrm{p}<0.01)$ following UVB radiation (Fig. 1A). Moreover, the foldinduction of cells into $\mathrm{G} 2 / \mathrm{M}$ arrest is significantly reduced in $\mathrm{KM}\left(\mathrm{MSH}^{-/}\right)$cells compared to JMG $\left(\mathrm{MSH}^{+/+}\right)$cells at $72 \mathrm{~h}$ post-UVB (1.2-fold induction versus 2 -fold induction respectively; $\mathrm{p}<0.05$; Fig. 1B). These findings are in agreement with previous studies using 6-TG and IR to induce DNA damage $(27,50)$. This partial reduction in $\mathrm{G} 2 / \mathrm{M}$ arrest is predicted to contribute, along with reduced apoptosis and repair, to the development of neoplasia in the absence of MMR (reviewed in refs. 9,51,52). Our data are consistent with the model that suggests a mechanism by which MMR acts upstream in G2/M arrest and apoptosis following DNA damage. In response to UVB radiation the MMR protein MSH2 binds to DNA lesions and may recruit cell cycle proteins, thus affecting the initiation of the G2/M cell cycle arrest cascade. Studies by Hays et al show that human MutS $\alpha$ and E. coli MutS bind to DNA that contains 'matched' photoproducts [T(CPD)T/AA, T(6-4PP)T/AA] as efficiently as it does to homoduplex DNA (53). In certain contexts these MMR complexes bind selectively to 'mismatched' photoproducts $[\mathrm{T}(\mathrm{CPD}) \mathbf{T} / \mathrm{A} \mathbf{G}, \mathrm{T}(6-4 \mathrm{PP}) \mathbf{T} / \mathrm{A} \mathbf{G}]$, but with no excision of the damage. Hays suggests that this formation of 'dead-end intermediates' may be a mechanism for the initiation of signaling by the MMR system.

Our data show a reduction in spontaneous levels of the key cell cycle regulators CHK1, CHK1phos (Ser345), CDC25C, CDC2, and CDC2phos (Tyr15, Thr14) in untreated $\mathrm{KM}\left(\mathrm{MSH}^{-/ /}\right)$cells compared to JMG $\left(\mathrm{MSH}^{+/+}\right)$cells. There are also relatively reduced amounts of CHK1phos (Ser345), CDC25Cphos (Ser216), CDC2phos (Tyr15, Thr14) and WEE1 after UVB-induced DNA damage in $\mathrm{KM}\left(\mathrm{MSH}^{-/-}\right)$cells compared to JMG $\left(\mathrm{MSH}^{+/+}\right)$cells. The reduction in CDC2phos (Tyr15, Thr14) in MSH2 deficient cells after UVB-induced DNA damage occurred at timepoints which corresponded to reduced G2/M arrest (Fig. 2). This is in agreement with Yan et al who determined that MMRdeficient cell lines exhibit rapidly decreasing levels of Cdc2phos (Tyr15) after high doses of IR, which corresponds temporally to IR-induced G2/M arrest (27). It was previously demonstrated that $\mathrm{MSH} 2$ co-immunoprecipitates with ATR and ATRIP, activating CHK1 following MNNG exposure $(33,35)$. MMR proteins may behave similarly in response to other DNA damaging agents. Therefore, following UVB radiation MSH2 may directly influence ATR and CHK1 activation, contributing to protein complex formation necessary for ATM/ATR activation and induction of G2/M arrest through the CDC2 pathway. Immunoblots to observe total and activated ATR were also investigated in this study, however due to the high amount of background signal and non-specific banding that occurred no conclusions could be made regarding levels of expression of these proteins in the cell lysates. Support for the recruitment of this pathway was additionally demonstrated by reduction in CHK1phos (Ser345) and CDC25Cphos
(Ser216) and WEE1 in MMR deficient cells after UVB treatment (Fig. 2). However, as MMR deficiency only partially decreases the G2/M cell cycle arrest, ATM/ATR are predicted to be activated by MMR-independent mechanisms as well.

The antibody used to recognize phosphorylated CDC2 (Tyr15) resulted in a reproducible doublet on immunoblots (Fig. 2). This doublet is most likely due to a second phosphorylation event at Thr14 also associated with inhibition of CDC2. The lower band reflects Tyr15 phosphorylation, and the upper band likely reflects both Thr14 and Tyr15 phosphorylation. A similar pattern was seen with WEE1. The antibody used detects both the unmodified form of WEE1 and the isoform phosphorylated at Ser549 by CHK1. The upper band is associated with phosphorylated WEE1 and the lower band represents the unphosphorylated form of WEE1.

The tumor suppressor p53 is involved in signaling apoptosis and cell cycle checkpoints following exposure to many different endogenous and exogenous DNA damaging agents. Following activation of ATM/ATR, CHK1 and CHK2 phosphorylate $\mathrm{p} 53$ at multiple sites, promoting its stabilization and activation (54-56). Activated p53 then upregulates 14-3-3 proteins that are involved in the sequestration of CDC2 and CDC25C in the cytoplasm, promoting G2/M arrest (57). Phosphorylation of p53 at serine 15 is a significant event after UVB exposure. We compared the levels of p53 and activated p53 (Ser15) following UVB irradiation of JMG $\left(\mathrm{MSH}^{+/+}\right)$ and $\mathrm{KM}\left(\mathrm{MSH}^{-/}\right)$cells (Fig. 3). Both untreated and UVBtreated $\mathrm{KM}\left(\mathrm{MSH}^{---}\right)$cells had diminished levels of total p53 compared to JMG $\left(\mathrm{MSH}^{+/+}\right)$cells. The levels of p53phos (Ser15) were near equal at $8 \mathrm{~h}$ after UVB radiation between $\mathrm{KM}\left(\mathrm{MSH}^{-/}\right)$and JMG $\left(\mathrm{MSH}^{+/+}\right)$cell lines, however, at $24 \mathrm{~h}$ the levels were greatly decreased with no continued induction of p53phos (Ser15) in the KM $\left(M_{S H} 2^{-/}\right)$cells. Therefore, MSH2 appears to contribute to the continued induction of the p53 response, but is not required for the initial activation of p53 following UVB radiation. In a recent study, it was demonstrated that phosphorylation of p53 occurred in response to temozolomide (TMZ), and was dependent on a functional MMR system in cells exposed to low drug concentrations (58). After treatment with methylating agents such as MNNG, MNU, and TMZ, it has been shown that MMR deficient cells do not stabilize p53 via phosphorylation on Ser15 and Ser392. These cells fail to undergo G2/M arrest and also do not undergo apoptosis in response to drug concentrations that effectively kill MMR-proficient cells (43-46). In our study, after treatment with UVB Ser15 phosphorylation of p53 still occurred in MMR-deficient cells, although the response was not sustained as in MMR-proficient cells (Fig. 3). Therefore, MMR proteins are important in p53 phosphorylation and stabilization after UVB-induced DNA damage.

p21 is one of the major downstream transcriptional targets of p53; p21 binds to Cyclin-Cdk complexes, leading to subsequent inhibition of their kinase activity and induction of cell cycle arrest $(59,60)$. Levels of UVB-induced p21 accumulation were decreased in the $\mathrm{MSH}^{-/-}$cell line $\mathrm{KM}$ (24 and 48 h; Fig. 4) compared to JMG $\left(\mathrm{MSH}^{+/+}\right.$), a pattern similar to that observed for p53 activation. While the JMG $\left(\mathrm{MSH}^{+/+}\right)$cell line showed increasing levels of $\mathrm{p} 21$ protein from 12 to $48 \mathrm{~h}$ after UVB irradiation, the $\mathrm{KM}\left(\mathrm{MSH}^{-/}\right)$cell line showed steadily decreasing p21 levels from 12 to $48 \mathrm{~h}$ 
after UVB radiation, consistent with the pattern of p53 expression.

When investigating the levels of p53 following UVB radiation, a slower migrating p53 band was observed in the $\mathrm{KM}\left(\mathrm{MSH}_{2}^{-/}\right)$cell line versus the JMG $\left(\mathrm{MSH}^{+/+}\right)$cell line. The MSH2-proficient cells had a band at the expected $53 \mathrm{kDa}$ size, while KM $\left(\mathrm{MSH}^{-/}\right)$cells demonstrated a band that migrated slower. A slower migrating band also occurred in the HEC1A (MSH6 ${ }^{-/}$, PMS2 $2^{-/}$endometrial adenocarcinoma) and the HEC59 $\left(\mathrm{MSH}^{-/}\right.$endometrial adenocarcinoma) cell lines, in addition to a lower band that migrated faster. An altered migration pattern was not observed in another MSH2 null cell line: Lovo ( $M S H 2^{-/-}$colon adenocarcinoma) or in the MMR-proficient cell line. This indicates that the slower migration of p53 in KM $\left(\mathrm{MSH}^{-/}\right)$may be an MMRdependent event, but not an MSH2-specific event (Fig. 5). The p53 cDNA was sequenced in both JMG $\left(\mathrm{MSH}^{+/+}\right)$and $\mathrm{KM}$ $\left(\mathrm{MSH}^{-/-}\right)$cell lines. Sequence analysis demonstrated that both cell lines had identical wild-type sequences for p53 (data not shown), thus the migration difference observed in $\mathrm{KM}\left(\mathrm{MSH}^{-/-}\right)$is not due to a coding mutation or splice site variation. Therefore, the reduced migration in $\mathrm{KM}\left(\mathrm{MSH}^{-/}\right)$ is attributed to altered post-translational modifications. p53 is regulated through many such modifications including phosphorylation, acetylation, methylation, ubiquitination, sumoylation and ribosylation. These processes regulate p53 activation, stabilization, cellular localization and degradation within the cell (reviewed in refs. 61-63). Treatment of JMG $\left(\mathrm{MSH}^{+/+}\right)$and $\mathrm{KM}\left(\mathrm{MSH}_{2} \mathrm{H}^{-/}\right)$cellular lysates with calf intestinal phosphatase showed that the alteration in migration of p53 is independent of phosphorylation (Fig. 6). Analysis of the glycosylation status of the cell lines revealed that the slower migration of p53 in $\mathrm{KM}\left(\mathrm{MSH}^{-/}\right)$is also independent of glycosylation; the $\mathrm{KM}\left(\mathrm{MSH}^{-/}\right)$cell line failed to exhibit increased fluorescence when compared to the MMRcompetent cell lines: JMG, MM and MR (data not shown). It is unlikely that the slower migration is due to ubiquitination or sumoylation because ubiquitin is an $8 \mathrm{kDa}$ protein and SUMO- 1 is an $11 \mathrm{kDa}$ protein, which are not consistent with the estimated $4 \mathrm{kDa}$ size increase observed in p53 in $\mathrm{KM}$ $\left(\mathrm{MSH}^{--/}\right)$. The slower migration in p53 in the KM $\left(\mathrm{MSH}^{-/}\right)$ cell line is likely due to an increase in the smaller covalent modifications. Studies are currently underway to examine acetylation, methylation or ribosylation.

We have demonstrated that lack of MSH2 in human non-tumor lymphoblastoid cells leads to diminished G2/M cell cycle arrest post-UVB and decreased induction of several integral cell cycle proteins, including p53. This evidence establishes that the MMR system is an important component in the cellular response to UVB-induced DNA damage. MMRdeficient cells can still undergo partial G2/M arrest; however, the diminished response may contribute in part to the observation that UVB induces skin tumors at a lower cumulative dose in MMR-null mice than in wild-type $(16,18,19)$. We also analyzed a previously uncharacterized p53 modification that may be MMR-dependent. Our findings, in addition to those by other groups, support a role for MMR in triggering a cascade of events that leads to cell cycle checkpoints post-UVB.

\section{Acknowledgements}

We wish to acknowledge the Canadian Institutes of Health Research for funding support. K.E.A.F. was supported by an Alberta Cancer Board studentship. A.A.M.P. was supported by a summer studentship by Alberta Heritage Foundation for Medical Research (AHFMR). S.E.A. is an AHFMR scholar. We would like to thank Dr A. Clark, NIEHS, for kindly supplying the HEC59 cells, and Dr Leah C. Young for assistance in figure formatting, statistics, and for critical reading of this manuscript.

\section{References}

1. Jacob $\mathrm{S}$ and Praz F: DNA mismatch repair defects: role in colorectal carcinogenesis. Biochimie 84: 27-47, 2002.

2. Aquilina $\mathrm{G}$ and Bignami $\mathrm{M}$ : Mismatch repair in correction of replication errors and processing of DNA damage. J Cell Physiol 187: 145-154, 2001.

3. Bellacosa A: Functional interactions and signaling properties of mammalian DNA mismatch repair proteins. Cell Death Differ 8: 1076-1092, 2001.

4. Jiricny J: The multifaceted mismatch-repair system. Nat Rev Mol Cell Biol 7: 335-346, 2006.

5. de Wind N, Dekker M, Berns A, Radman M and te Riele H: Inactivation of the mouse Msh2 gene results in mismatch repair deficiency, methylation tolerance, hyperrecombination, and predisposition to cancer. Cell 82: 321-330, 1995.

6. Hawn MT, Umar A, Carethers JM, et al: Evidence for a connection between the mismatch repair system and the $\mathrm{G} 2$ cell cycle checkpoint. Cancer Res 55: 3721-3725, 1995.

7. Duckett DR, Drummond JT, Murchie AI, et al: Human MutSalpha recognizes damaged DNA base pairs containing O6-methylguanine, O4-methylthymine, or the cisplatin-d(GpG) adduct. Proc Natl Acad Sci USA 93: 6443-6447, 1996.

8. Karran P: Mechanisms of tolerance to DNA damaging therapeutic drugs. Carcinogenesis 22: 1931-1937, 2001

9. Young LC, Hays JB, Tron VA and Andrew SE: DNA mismatch repair proteins: potential guardians against genomic instability and tumorigenesis induced by ultraviolet photoproducts. J Invest Dermatol 121: 435-440, 2003

10. Mu D, Tursun M, Duckett DR, Drummond JT, Modrich P and Sancar A: Recognition and repair of compound DNA lesions (base damage and mismatch) by human mismatch repair and excision repair systems. Mol Cell Biol 17: 760-769, 1997.

11. Wang H, Lawrence CW, Li GM and Hays JB: Specific binding of human MSH2.MSH6 mismatch-repair protein heterodimers to DNA incorporating thymine- or uracil-containing UV light photoproducts opposite mismatched bases. J Biol Chem 274: 16894-16900, 1999

12. Iyer RR, Pluciennik A, Burdett V and Modrich PL: DNA mismatch repair: functions and mechanisms. Chem Rev 106 302-323, 2006.

13. Drotschmann K, Topping RP, Clodfelter JE and Salsbury FR Mutations in the nucleotide-binding domain of MutS homologs uncouple cell death from cell survival. DNA Repair 3: 729-742, 2004.

14. Lin DP, Wang Y, Scherer SJ, et al: An Msh2 point mutation uncouples DNA mismatch repair and apoptosis. Cancer Res 64: 517-522, 2004.

15. Yang G, Scherer SJ, Shell SS, et al: Dominant effects of an Msh6 missense mutation on DNA repair and cancer susceptibility. Cancer Cell 6: 139-150, 2004.

16. Young LC, Thulien KJ, Campbell MR, Tron VA and Andrew SE: DNA mismatch repair proteins promote apoptosis and suppress tumorigenesis in response to UVB irradiation: an in vivo study. Carcinogenesis 25: 1821-1827, 2004.

17. Peters AC, Young LC, Maeda T, Tron VA and Andrew SE: Mammalian DNA mismatch repair protects cells from UVBinduced DNA damage by facilitating apoptosis and p53 activation. DNA Repair 2: 427-435, 2003.

18. Meira LB, Cheo DL, Reis AM, et al: Mice defective in the mismatch repair gene Msh2 show increased predisposition to UVB radiation-induced skin cancer. DNA Repair 1: 929-934, 2002. 
19. Yoshino M, Nakatsu Y, te Riele H, Hirota S, Kitamura Y and Tanaka K: Additive roles of XPA and MSH2 genes in UVBinduced skin tumorigenesis in mice. DNA Repair 1: 935-940, 2002.

20. van Oosten M, Stout GJ, Backendorf C, et al: Mismatch repair protein Msh2 contributes to UVB-induced cell cycle arrest in epidermal and cultured mouse keratinocytes. DNA Repair 4: 8189,2005

21. Young LC, Peters AC, Maeda T, et al: DNA mismatch repair protein Msh6 is required for optimal levels of ultraviolet-Binduced apoptosis in primary mouse fibroblasts. J Invest Dermatol 121: 876-880, 2003

22. Zhang H, Taylor J and Siede W: Checkpoint arrest signaling in response to UV damage is independent of nucleotide excision repair in Saccharomyces cerevisiae. J Biol Chem 278: 9382-9387, 2003.

23. Sancar A, Lindsey-Boltz LA, Unsal-Kacmaz K and Linn S: Molecular mechanisms of mammalian DNA repair and the DNA damage checkpoints. Annu Rev Biochem 73: 39-85, 2004.

24. Taylor WR and Stark GR: Regulation of the G2/M transition by p53. Oncogene 20: 1803-1815, 2001

25. Davis TW, Wilson-Van Patten C, Meyers M, et al: Defective expression of the DNA mismatch repair protein, MLH1, alters G2-M cell cycle checkpoint arrest following ionizing radiation. Cancer Res 58: 767-778, 1998.

26. Franchitto A, Pichierri P, Piergentili R, Crescenzi M, Bignami M and Palitti F: The mammalian mismatch repair protein MSH2 is required for correct MRE11 and RAD51 relocalization and for efficient cell cycle arrest induced by ionizing radiation in G2 phase. Oncogene 22: 2110-2120, 2003.

27. Yan T, Schupp JE, Hwang HS, et al: Loss of DNA mismatch repair imparts defective cdc2 signaling and $G(2)$ arrest responses without altering survival after ionizing radiation. Cancer Res 61: 8290-8297, 2001

28. Reitmair AH, Risley R, Bristow RG, et al: Mutator phenotype in Msh2-deficient murine embryonic fibroblasts. Cancer Res 57: 3765-3771, 1997

29. Yan T, Berry SE, Desai AB and Kinsella TJ: DNA mismatch repair (MMR) mediates 6-thioguanine genotoxicity by introducing single-strand breaks to signal a G(2)-M arrest in MMR-proficient RKO cells. Clin Cancer Res 9: 2327-2334, 2003.

30. Meyers M, Wagner MW, Hwang HS, Kinsella TJ and Boothman DA: Role of the hMLH1 DNA mismatch repair protein in fluoropyrimidine-mediated cell death and cell cycle responses. Cancer Res 61: 5193-5201, 2001.

31. Umar A, Koi M, Risinger JI, et al: Correction of hypermutability, N-methyl-N'-nitro-N-nitrosoguanidine resistance, and defective DNA mismatch repair by introducing chromosome 2 into human tumor cells with mutations in MSH2 and MSH6. Cancer Res 57: 3949-3955, 1997.

32. Koi M, Umar A, Chauhan DP, et al: Human chromosome 3 corrects mismatch repair deficiency and microsatellite instability and reduces $\mathrm{N}$-methyl- $\mathrm{N}$-nitro- $\mathrm{N}$-nitrosoguanidine tolerance in colon tumor cells with homozygous hMLH1 mutation. Cancer Res 54: 4308-4312, 1994.

33. Adamson AW, Beardsley DI, Kim WJ, Gao Y, Baskaran R and Brown KD: Methylator-induced, mismatch repair-dependent G2 arrest is activated through Chk1 and Chk2. Mol Biol Cell 16: 1513-1526, 2005

34. Brown KD, Rathi A, Kamath R, et al: The mismatch repair system is required for S-phase checkpoint activation. Nat Genet 33: 80-84, 2003.

35. Wang $\mathrm{Y}$ and Qin J: MSH2 and ATR form a signaling module and regulate two branches of the damage response to DNA methylation. Proc Natl Acad Sci USA 100: 15387-15392, 2003.

36. Bhattacharyya NP, Skandalis A, Ganesh A, Groden J and Meuth M: Mutator phenotypes in human colorectal carcinoma cell lines. Proc Natl Acad Sci USA 91: 6319-6323, 1994.

37. Branch P, Hampson R and Karran P: DNA mismatch binding defects, DNA damage tolerance, and mutator phenotypes in human colorectal carcinoma cell lines. Cancer Res 55: 2304-2309, 1995.

38. Malkhosyan S, McCarty A, Sawai H and Perucho M: Differences in the spectrum of spontaneous mutations in the hprt gene between tumor cells of the microsatellite mutator phenotype. Mutat Res 316: 249-259, 1996.

39. Richards B, Zhang H, Phear G and Meuth M: Conditional mutator phenotypes in hMSH2-deficient tumor cell lines. Science 277: 1523-1526, 1997.
40. Whiteside D, McLeod R, Graham G, et al: A homozygous germ-line mutation in the human MSH2 gene predisposes to hematological malignancy and multiple cafe-au-lait spots. Cancer Res 62: 359-362, 2002.

41. Matlashewski GJ, Tuck S, Pim D, Lamb P, Schneider J and Crawford LV: Primary structure polymorphism at amino acid residue 72 of human p53. Mol Cell Biol 7: 961-963, 1987.

42. Thomas M, Kalita A, Labrecque S, Pim D, Banks L and Matlashewski G: Two polymorphic variants of wild-type p53 differ biochemically and biologically. Mol Cell Biol 19: 1092-1100, 1999.

43. Kaina B, Ziouta A, Ochs K and Coquerelle T: Chromosomal instability, reproductive cell death and apoptosis induced by O6-methylguanine in Mex-, Mex+ and methylation-tolerant mismatch repair compromised cells: facts and models. Mutat Res 381: 227-241, 1997.

44. D'Atri S, Tentori L, Lacal P M, et al: Involvement of the mismatch repair system in temozolomide-induced apoptosis. Mol Pharmacol 54: 334-341, 1998.

45. Duckett DR, Bronstein SM, Taya Y and Modrich P: hMutSalphaand hMutLalpha-dependent phosphorylation of p53 in response to DNA methylator damage. Proc Natl Acad Sci USA 96 12384-12388, 1999

46. Hickman MJ and Samson LD: Role of DNA mismatch repair and p53 in signaling induction of apoptosis by alkylating agents. Proc Natl Acad Sci USA 96: 10764-10769, 1999.

47. Hirose Y, Katayama M, Stokoe D, Haas-Kogan DA, Berger MS, and Pieper RO: The p38 mitogen-activated protein kinase pathway links the DNA mismatch repair system to the G2 checkpoint and to resistance to chemotherapeutic DNAmethylating agents. Mol Cell Biol 23: 8306-8315, 2003.

48. Modrich P: Strand-specific mismatch repair in mammalian cells. J Biol Chem 272: 24727-24730, 1997.

49. Matsumura Y and Ananthaswamy HN: Short-term and longterm cellular and molecular events following UV irradiation of skin: implications for molecular medicine. Expert Rev Mol Med 12: 1-22, 2002.

50. Buermeyer AB, Deschenes SM, Baker SM and Liskay RM: Mammalian DNA mismatch repair. Annu Rev Genet 33: 533-564, 1999.

51. O'Brien V and Brown R: Signalling cell cycle arrest and cell death through the MMR System. Carcinogenesis 27: 682-692, 2006.

52. Seifert $M$ and Reichrath J: The role of the human DNA mismatch repair gene hMSH2 in DNA repair, cell cycle control and apoptosis: implications for pathogenesis, progression and therapy of cancer. J Mol Histol 37: 301-307, 2006.

53. Hays JB, Hoffman PD and Wang H: Discrimination and versatility in mismatch repair. DNA Repair 4: 1463-1474, 2005.

54. Chehab NH, Malikzay A, Appel M and Halazonetis TD: Chk2/hCds1 functions as a DNA damage checkpoint in $\mathrm{G}(1)$ by stabilizing p53. Genes Dev 14: 278-288, 2000.

55. Hirao A, Kong YY, Matsuoka S, et al: DNA damage-induced activation of $\mathrm{p} 53$ by the checkpoint kinase Chk2. Science 287 : 1824-1827, 2000

56. Shieh SY, Ahn J, Tamai K, Taya Y and Prives C: The human homologs of checkpoint kinases Chk1 and Cds1 (Chk2) phosphorylate p53 at multiple DNA damage-inducible sites. Genes Dev 14: 289-300, 2000

57. Lopez-Girona A, Kanoh J and Russell P: Nuclear exclusion of Cdc25 is not required for the DNA damage checkpoint in fission yeast. Curr Biol 11: 50-54, 2001

58. Caporali S, Falcinelli S, Starace G, et al: DNA damage induced by temozolomide signals to both ATM and ATR: role of the mismatch repair system. Mol Pharmacol 66: 478-491, 2004.

59. Harper JW, Elledge SJ, Keyomarsi K, et al: Inhibition of cyclindependent kinases by p21. Mol Biol Cell 6: 387-400, 1995.

60. el-Deiry WS, Tokino T, Velculescu VE, et al: WAF1, a potential mediator of p53 tumor suppression. Cell 75: 817-825, 1993.

61. Appella E and Anderson CW: Post-translational modifications and activation of $\mathrm{p} 53$ by genotoxic stresses. Eur J Biochem 268: 2764-2772, 2001

62. Brooks $\mathrm{CL}$ and $\mathrm{Gu} \mathrm{W}$ : Ubiquitination, phosphorylation and acetylation: the molecular basis for p53 regulation. Curr Opin Cell Biol 15: 164-171, 2003.

63. Meek DW: The p53 response to DNA damage. DNA Repair (Amst) 3: 1049-1056, 2004

64. Pietenpol JA and Stewart ZA: Cell cycle checkpoint signaling: cell cycle arrest versus apoptosis. Toxicology 181-182: 475-481, 2002. 